\title{
Improved underground utilities asset management - assessing the impact of the UK utility survey standard (PAS128)
}

Nicole Metje Dipl.-Eng, PhD, MCInstCES, MASCE, FHEA Professor of Infrastructure Monitoring, Head of the Power and Infrastructure Research Group, Department of Civil Engineering, School of Engineering, University of Birmingham, Birmingham, UK (Orcid:0000-0002-6741-8183)

Aryan Hojjati MEng, GMICE, AFHEA

Research Fellow in Sustainable Infrastructure and Materials, Department of Civil Engineering, School of Engineering, University of Birmingham,

Birmingham, UK (corresponding author: a.hojjati@bham.ac.uk)

(Orcid:0000-0002-2928-5025)
Anthony Beck BA, PhD

Director, GeoLytics Ltd., Outwood, UK (Orcid:0000-0002-2991-811X)

Christopher D. F. Rogers Eur Ing, BSC, PhD, CEng, MICE, FCIHT,

FHEA

Professor of Geotechnical Engineering, Director of the UKCRIC National Buried Infrastructure Facility, Department of Civil Engineering, School of Engineering, University of Birmingham, Birmingham, UK (Orcid:0000-0002-1693-1999)

Buried utilities (e.g. gas, water, electricity, drainage), many installed decades ago, are vital urban support systems. Their locations are often not well documented, yet accurate location greatly helps replacement, rehabilitation and maintenance of existing services and is crucial for installation of new utilities: it minimises utility strikes / third party damage and the huge associated costs of delayed / additional streetworks. Several international standards and specifications aim to provide guidance on utility surveys to increase client confidence in their accuracy and repeatability. The most recent specification is PAS (Publicly Available Specification) 128 in the UK for underground utility detection, verification and location. This paper investigates the impact of PAS128 by comparing trial site survey results from different utility survey specialists with each other and with the vertical and horizontal accuracies at trial excavations. While the overall detection level was very good for all companies, the research revealed that the definition of quality level QLB1 needs to be reconsidered as it was not achieved in many places with respect to the vertical accuracy. It is recommended that future revisions of PAS128 differentiate between accuracy and confidence since detection by multiple sensing technologies increases the confidence, but not the accuracy as suggested by PAS128.

\section{Introduction}

A vast network of buried utilities exists underneath roads and pedestrian areas around the world, which need maintenance, rehabilitation and/or replacement. Najafi (2005) stated that more than $480000 \mathrm{~km}$ of utility pipelines and cables are laid globally each year. Combined, the UK buried utilities network (electricity, water, sewers, gas and telecommunications) exceeds 1.5 million kilometres (Parker, 2008b), necessitating 1.37 million streetworks by utility companies in 2014-2015 alone (Gallienne, 2016). The problem of incomplete and inaccurate utility records, and inaccurate detection and location of buried pipes and cables on site, exacerbates the multiple adverse impacts of utility streetworks arising from traffic disruption and physical disturbance to a complex road-ground-utility ecosystem, particularly in cases of unplanned streetworks overruns (McMahon et al., 2006). Moreover, the problem is getting worse as existing buried infrastructure ages, maintenance regimes fail to keep up and demands for services grow, yielding increasing numbers of utility streetworks operations globally (Metje et al., 2007). Alongside the social and physical disruption, there are significant health and safety risks associated with damage to existing (unexpected) underground assets, while utility strikes yield enormous direct economic costs and indirect social and environmental costs (Makana et al., 2018; Metje et al., 2015).

The problem of inaccurate, incomplete or outdated information on buried utility assets, as well as the historical unreliability and slow-paced location and detection operations, were identified by Ashdown (2001) as serious barriers to the utility infrastructure industry and established the need for collaborative research combining the utility industry, government and academia (Parker, 2008a). One such initiative was Mapping The Underworld (MTU), which aimed to develop a multi-sensor device and other associated tools to locate, position and record all buried assets without the need for excavation (MTU, 2013). Established in 2004, MTU resulted from a number of industry-academe workshops supported by the Engineering Programme Network in Trenchless Technology (NETTWORK; see Chapman et al., 2002; Metje et al., 2007; Rogers and Chapman, 2005; Rogers et al., 2004) as well as a series of stakeholders' meetings and consultations (Burtwell et al., 2003; Thomas et al., 2009). MTU received its first substantial project funding from the UK 
Government for the multi-sensor device project in 2008 (Royal et al., 2010). Although the project successfully advanced different detection techniques and developed an integrated multidevice platform, problems remained in terms of inaccurate and out-dated statutory records and drawings, and variability in defining the term 'utility survey' and hence the level of confidence in the data from different utility surveys. However, parallel initiatives (development of diploma-level courses for utility survey practitioners, and the national testing and training facility designed by MTU and implemented by JK Guest Limited) and the drive by practitioners to professionalise their industry all served to advance surveying outcomes significantly (Metje et al., 2013).

One key issue has always been the lack of a UK standard for utility practitioners, although standards and specifications designed to address some of these issues had been developed and implemented in other countries since 2002. The USA was the first to standardise surveying practices, where the American Society of Civil Engineers (ASCE) developed guidelines for the collection and depiction of existing subsurface utility data, known as ASCE 38/02 (ASCE, 2002). This was driven by the emergence of subsurface utility engineering (SUE) as a professional discipline, which adopted practices that aimed to better characterise the quality of subsurface utility information and manage the associated risks (Zembillas, 2003). Malaysia adopted most of ASCE38/02 (ASCE, 2002) in its standard, making only minor adjustments to the Malaysian contractual arrangements in 2006 (JUPEM, 2006). In 2011 the Canadian Standards Institute published CSA S250-11 (CSA, 2011), which was revised in 2016. In 2013, Australia published its version of a utility standard: AS 5488-2013 (SA, 2013), which is currently being updated (SA, 2018). MTU and the UK industry promoted the need for the development of an industry standard for underground utility surveying in the UK, leading to the British Standards Institution developing a Publicly Available Specification (PAS). In 2014, PAS128 (BSI, 2014) for 'Underground Utility Detection, Verification and Location' was launched in the UK. It aims to provide

\footnotetext{
1. Clarity in the service provided and methods employed

2. Consistency in the approach to data capture

3. Classification of the results and the confidence that can be associated with them

4. Standardisation of the format of deliverables and

5. Accountability for the work undertaken.
}

The specification was developed for use by underground surveying practitioners, geophysicists and subsurface utility engineers, but should also be of interest to other utility streetworks stakeholders, including utility owners, project managers, contractors and site engineers (Makana et al., 2018). PAS128 closely follows other standards in that it uses four different quality levels $(\mathrm{QL})$ to differentiate the type of survey carried out or achieved

\section{QLA: Verification \\ - QLB: Detection \\ QLC: Site reconnaissance \\ - QLD: Desktop utility records research}

However, in contrast to the guidelines/standards in other countries, PAS128 goes further by requiring a minimum of two different techniques - usually ground penetrating radar (GPR) and electromagnetic locators (EML) - to be used for QLB (geophysical survey) and stating the horizontal and vertical accuracies for QLA and QLB. Moreover, it introduced subQLs for QLB (see Table 1) depending on the number of different sensing technologies that detected the asset as well as the received signal strength. The final classification is up to the professional practitioner, however.

There have been some attempts to quantify the impact of the guidelines and standards across the world, but most have focused on quantifying the return on investment (ROI) for carrying out a utility survey early in the construction phase. Examples include Lew (1999), Osman and El-Diraby (2005, 2007) and Sinha et al. (2007), who conducted similar studies using different methodologies in North Carolina, Ohio, Texas and Virginia States (USA), Ontario (Canada) and Pennsylvania (USA), respectively. All reported a positive ROI with average project cost savings ranging from $\$ 1.98$ to $\$ 22.21$ for every $\$ 1$ spent when SUE investigations were carried out. However, no research has determined the impact of the standards and guidelines across the world on the precision, accuracy and certainty with which the survey results are reported and whether they managed to support clients in obtaining more standardised utility survey results. It should be noted, however, that local districts and regions in the USA mainly rely on local policies rather than standards (e.g. ASCE 38/02) as guidance for the use of SUE (Kraus et al., 2012).

Ashdown (2001) reviewed the outcomes of utility surveys by geophysical instrument manufacturers on a road junction with a large variety of buried assets, which was subsequently excavated to verify the buried assets' locations. The detection rate ranged between 20 and $80 \%$, yet technologies have moved on since 2001 and tests performed by equipment manufacturers in isolation would be expected to be less effective than surveys by professional surveying companies. Thus to evaluate the impact of PAS128 (BSI, 2014), MTU invited a number of utility survey companies to carry out utility surveys at Glen Eyre Hall in Southampton on a site containing buried utilities beneath and adjacent to a car park. Proving excavations were carried out to reveal the subsurface assets and provide ground truth data at key locations once the surveys had been completed. 
Table 1. PAS128 (BSI, 2014) QLs, P for level QLB indicates post-processing

\begin{tabular}{|c|c|c|c|}
\hline Level & Meaning & Horizontal accuracy & Vertical accuracy \\
\hline (A) & $\begin{array}{l}\text { Verified by inspection - trial pit, vacuum excavation, inspection } \\
\text { chamber/manhole }\end{array}$ & $50 \mathrm{~mm}$ & $25 \mathrm{~mm}$ \\
\hline (B1/B1P) & $\begin{array}{l}\text { Horizontal and vertical positions detected with multiple } \\
\text { geophysical techniques, GPR and EML }\end{array}$ & $\begin{array}{l} \pm 150 \mathrm{~mm} \text { or } \pm 15 \% \text { of detected depth } \\
\text { whichever is greater }\end{array}$ & $\begin{array}{l} \pm 15 \% \text { of detected } \\
\text { depth }\end{array}$ \\
\hline (B2/B2P) & $\begin{array}{l}\text { Horizontal and vertical position detected with either one } \\
\text { geophysical technique, GPR or EML }\end{array}$ & $\begin{array}{l} \pm 250 \mathrm{~mm} \text { (or } \pm 40 \% \text { of detected depth } \\
\text { whichever is greater }\end{array}$ & $\begin{array}{l} \pm 40 \% \text { of detected } \\
\text { depth }\end{array}$ \\
\hline (B3/B3P) & $\begin{array}{l}\text { Horizontal position detected with only one of the geophysical } \\
\text { techniques used, GPR or EML }\end{array}$ & $\pm 500 \mathrm{~mm}$ & Undefined \\
\hline (B4) & $\begin{array}{l}\text { Assumed route (geophysical survey conducted, but no feature } \\
\text { detected) }\end{array}$ & Undefined & Undefined \\
\hline (C) & $\begin{array}{l}\text { Site reconnaissance to match physical features to statutory } \\
\text { records }\end{array}$ & Undefined & Undefined \\
\hline (D) & Desktop utility records search & Undefined & Undefined \\
\hline
\end{tabular}

The scope of this paper is to assess the impact PAS128 (BSI, 2014) has made on the survey industry in providing comparable results by presenting, analysing and comparing the results of utility surveys from four different utility survey companies. The surveys are assessed in relation to the designated QLs in PAS128 (BSI, 2014) at the trial pit locations and in terms of how achievable the accuracies defined in PAS128 QLB are, based on the criteria given in the specification. As such, it is believed to be the first research of its type evaluating any of the survey standards across the world.

\section{Study site and surveys methodology}

The survey area was a $15 \mathrm{~m} \times 20 \mathrm{~m}$ asphalt-covered car park with a grass surround on two sides (Figure 1), which was free of cars during testing. The site was chosen for scientific and operational reasons, being sufficiently complex at certain points to require distinction between services and at other points devoid of services. It is appreciated that more complex, denser utility arrangements will be encountered in practice, especially in urban centres, and that this might potentially influence the confidence that surveyors would have in their survey results, yet any uncertainty, and the reasons for this uncertainty, would be reported, hence made transparent.

The specified aim was to locate all buried assets and return the results in PAS128 format. The survey companies were provided with the statutory utility records (obtained from the University of Southampton) in advance and could choose the most appropriate sensing technologies (e.g. manufacturer, frequency) and grid spacing, but were not allowed to use trial excavations (QLA) at any stage in support of their surveys. However, manholes could be lifted at any time. Four companies carried out the geophysical survey and returned their results with respect to a local grid. Following the analysis of the commercial subsurface utility surveys, a number of locations were suggested for trial pit excavations. The aim of these excavations was to reveal the physical nature of the assets

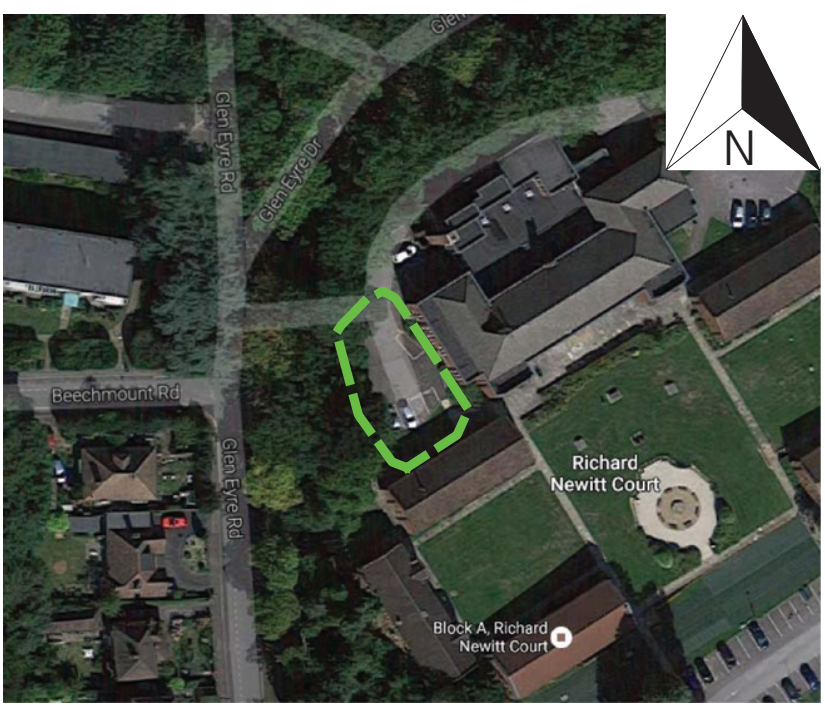

Figure 1. Glen Eyre study area. Aerial image courtesy of Google

detected by the subsurface scans and to evaluate whether the features detected were both complete and accurate. All data were captured in three dimensions - that is, plan locations and depths were recorded as related to a site grid. The trial pits were specifically located to confirm the presence/absence of recorded features and identify some key feature types.

Figure 2 shows that the survey companies used slightly different survey extents as the boundaries of the trial area were not well defined, and thus to compare on a like-by-like basis a control area was defined covered by all survey companies.

\section{Results of geophysical survey - comparison between utility survey companies}

Within this control area, the length of each utility type for each survey company was determined (see Figure 3). It should 

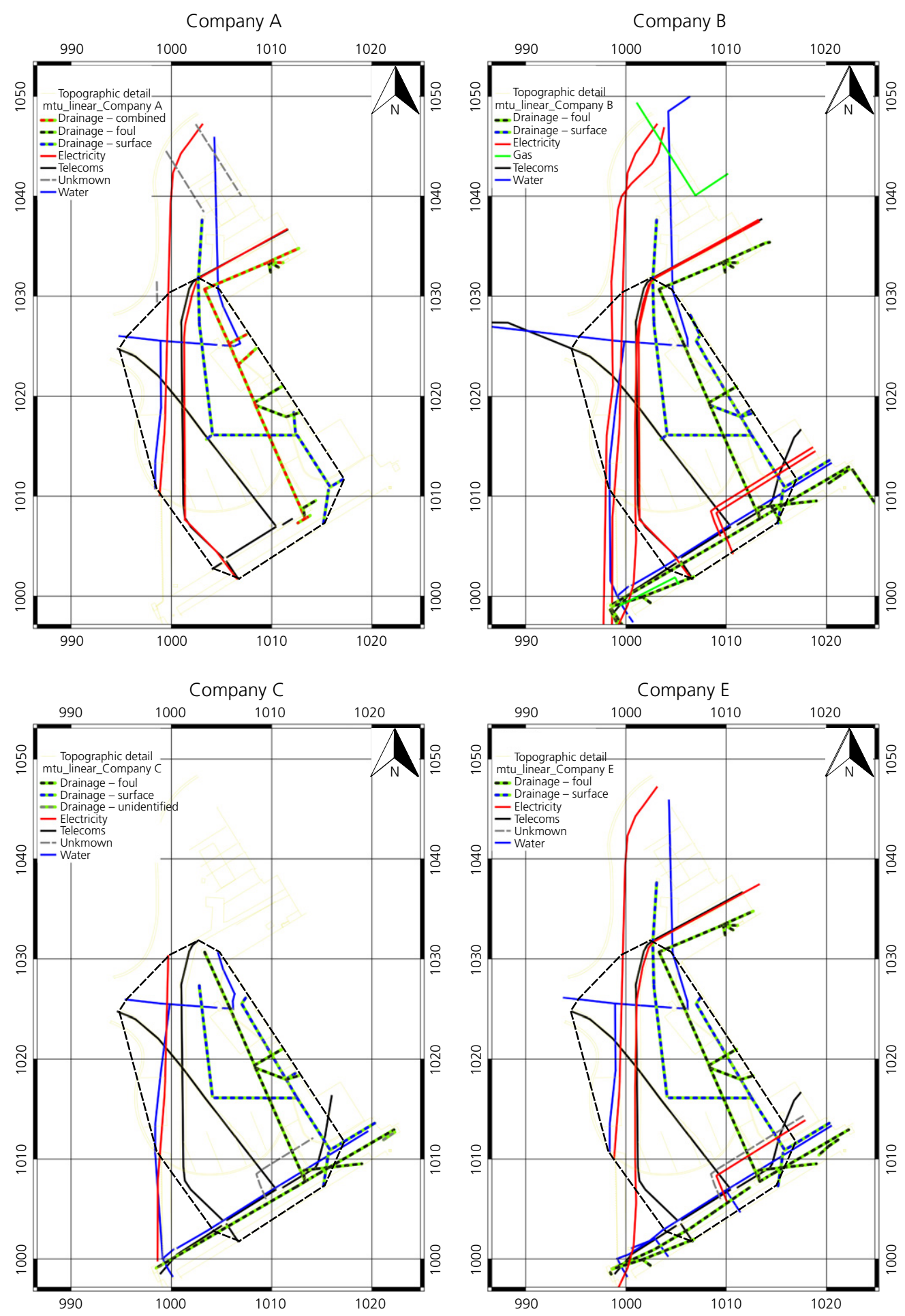

Figure 2. Detected utilities for the four different companies (note every image is at the same scale) 


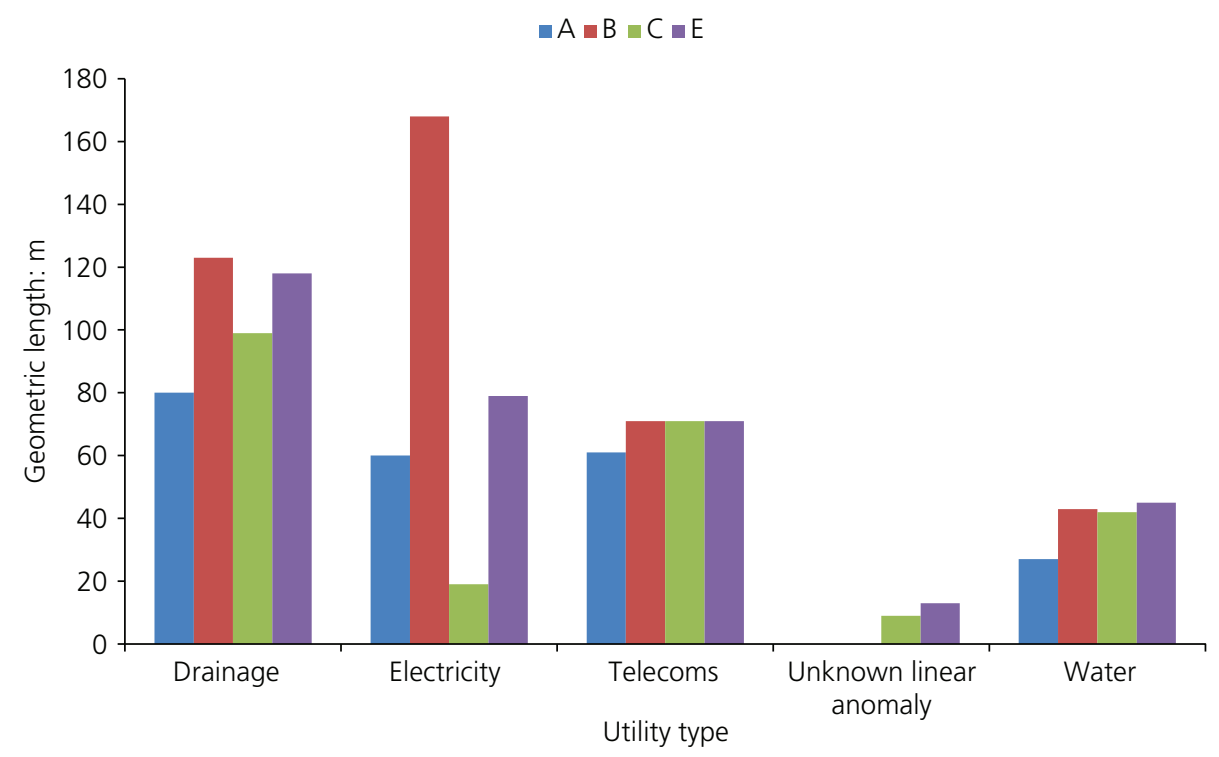

Figure 3. Total geometric length in metres by utility type detected by each survey company

be noted that at this stage, no judgement is made on the accuracy of the results - it simply reports the total length of the assets detected.

Overall, the results are very encouraging with little difference in the detection of the telecoms and water assets. The biggest differences were for the drainage and electricity utility network. The water network is mainly coherent with some minor disagreements in network connectivity. There are very consistent readings from companies $\mathrm{B}, \mathrm{C}$ and $\mathrm{E}$ for the telecoms interpretations. The drainage network has a range of observed lengths differing by up to $43 \mathrm{~m}$ ( $80 \mathrm{~m}$ observed by company A and $123 \mathrm{~m}$ from company B) and contains significant diversity in detection between the companies. Proximity to buildings appears to be one of the biggest problems for this utility type. On reviewing the results, it became apparent that some companies carried out surveys in the flower beds close to the building while others had not, thereby explaining some of the differences. The electricity network has a range of observed lengths differing by up to $149 \mathrm{~m}$ ( $19 \mathrm{~m}$ observed by company C and $168 \mathrm{~m}$ from company B).

Since the surveys were undertaken over a $9 \mathrm{~d}$ period in March 2015, their multi-temporal nature can have the following impact on detection

- Differences in detection can be affected by subsurface variations between survey dates (such as variations in soil-water or temperature). The daily mean temperature during those nine days varied by approximately $6^{\circ} \mathrm{C}$, while the daily rainfall on the first day was $4.4 \mathrm{~mm}$ with no significant rainfall on any further days.

- Differences in the detection of electricity assets can be as a result of different loading on the days of the survey, a factor that was impossible to determine.

In addition, it should be noted that survey companies can conflate multiple signal responses into a single detection event during interpretation. Company A clearly stated that 'a single line may represent multiple services in the same location'.

\section{Verification (trial pit) excavations}

To assess the accuracy of the quality level designations, focusing on QLB1 and QLB2, the location of the trial pits was designed to provide an insight into some of the key relationships identified by the subsurface survey: to confirm what was identified and, if possible, to locate features that were not identified (Figure 4). Not all as-designed trial pits were excavated due to in situ ground conditions, available resources and time constraints. While most of the relationships in the electricity and telecoms networks could still be tested, this did cause an issue for the verification of some features in the clean and foul (drainage) water network.

In total, 14 trial pits were excavated and the features exposed and their attributes were analysed in detail. Where a company specified a PAS128 quality level (BSI, 2014) the horizontal uncertainty is represented in the width of the lines in the 


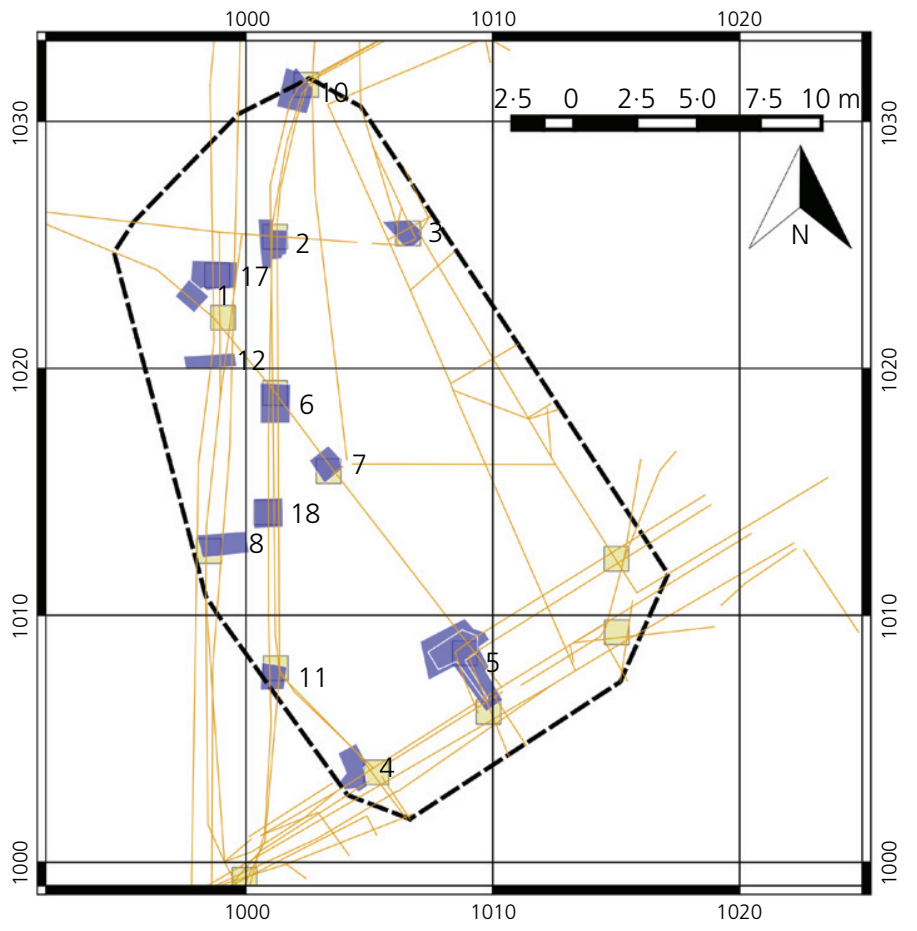

Figure 4. Excavated trial pit locations overlying the as-designed trial pits

drawings (see Figures 6-10). Details concerning whether the feature passes or fails its attributed PAS128 QLs are included in Table 2 for all the excavated trial pits. For example, PAS128 H:T and PAS128 V:F means that the horizontal $(\mathrm{H})$ passes the PAS128 specification (it is true (T)) while the vertical (V) fails the PAS128 specification (it is false $(\mathrm{F})$ ).

Three trial pits, 2, 8 (combined with 18) and 10, are presented in more detail in this paper as examples to describe the analysis and illustrate the findings (see Figures 5, 7 and 9 respectively). Figure 5 shows trial pit 2, which contained water, electricity and telecoms networks. In Figure 5 the exposed asset is displayed using a thicker line, while the thinner line indicates how the exposed asset is extrapolated to the next trial pit. For the electricity network trial pit 2 is between trial pits 6 and 10 (see Figure 4), each of which contains at least two interpreted electricity cables. It would be logical to expect trial pit 2, as an intermediary excavation, to contain two interpreted electricity cables. It is also clear from the photographs that the backfill east of the $\mathrm{N}-\mathrm{S}$ conduit has only been excavated to the level of the first electricity cables. Hence, it has been classed as a partially excavated trial pit - that is, it has been inferred from the photograph (see Figure 5) and hence it is partially recorded. There is some spatial uncertainty about the location of the water pipe (V1) from the verification survey.
Figure 6 shows the detected features for the four survey companies, where the thickness of the lines indicates the horizontal uncertainty as expressed by the different PAS128 QLs. All four companies detected the water network. In undertaking trenching operations, excavation machinery is restricted to working at a safe distance from a suspected asset. In order to assess the severity of providing incorrect vertical and/or horizontal position data from a utility survey, a $500 \mathrm{~mm}$ machine bucket is used to determine risk when excavating and this is used throughout the paper as an indication of risk, although smaller bucket sizes are also regularly used, especially on mini-excavators, so this should be treated as indicative only. Based on the $500 \mathrm{~mm}$ bucket size, all companies provided adequate planimetric spatial information except company $\mathrm{C}$ : the horizontal position of the pipe located by company $\mathrm{C}$ is too far away. For their stated PAS128 QLs (BSI, 2014) all companies pass the horizontal and vertical specifications with the exception of company B, which failed the vertical specification. All other companies reported a quality level B2 (QLB2) while company B reported a QLB1; interestingly, company B would have passed the vertical specification at a B2 quality level.

Companies A, B and E detected the electricity network (cables V2 and V4). Company $\mathrm{C}$ did not detect this high-risk electricity asset at all. However, there remains some uncertainty with 

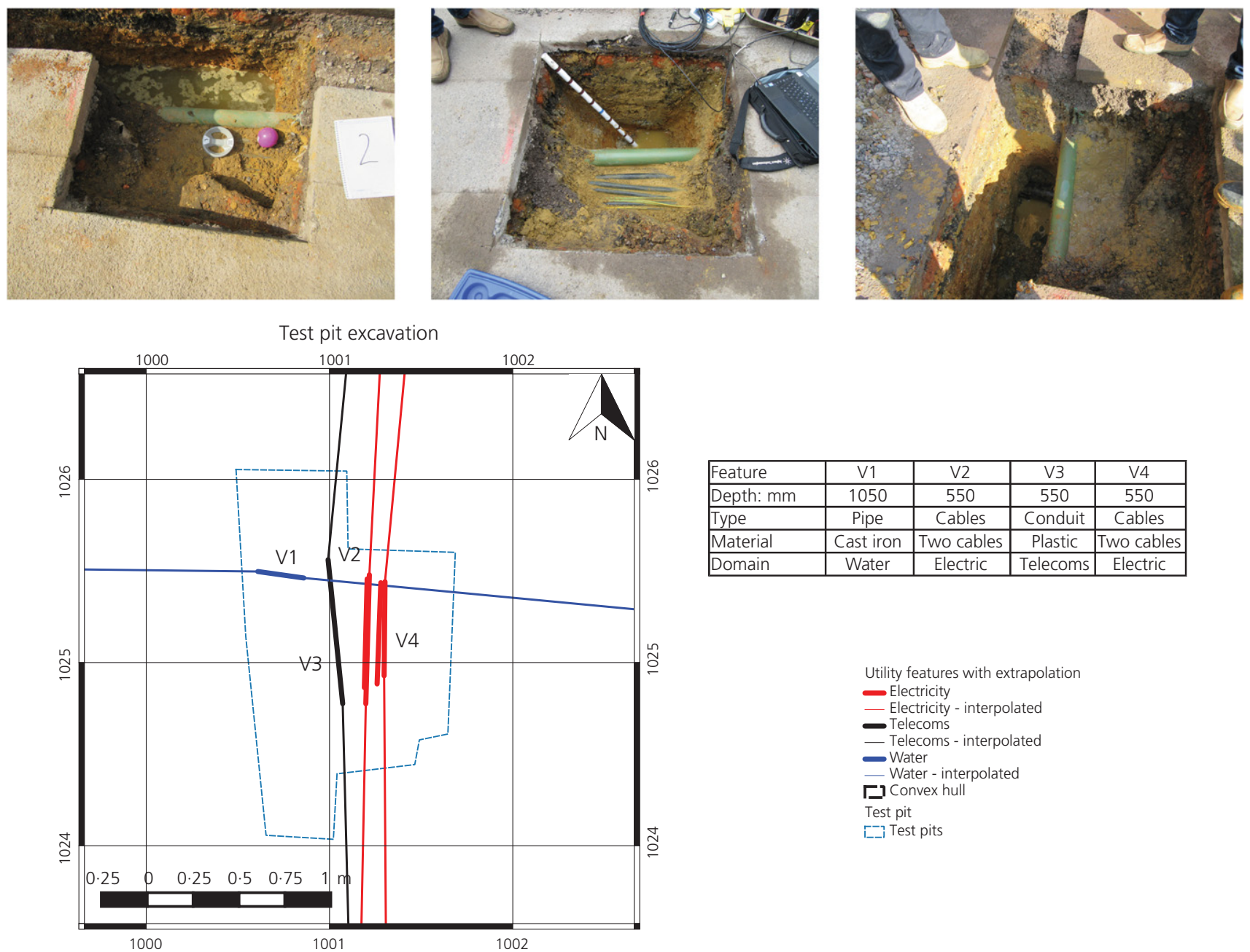

\begin{tabular}{|l|c|c|c|c|}
\hline Feature & V1 & V2 & V3 & V4 \\
\hline Depth: $\mathrm{mm}$ & 1050 & 550 & 550 & 550 \\
\hline Type & Pipe & Cables & Conduit & Cables \\
\hline Material & Cast iron & Two cables & Plastic & Two cables \\
\hline Domain & Water & Electric & Telecoms & Electric \\
\hline
\end{tabular}

$$
\begin{aligned}
& \text { Utility features with extrapolation } \\
& \text { Electricity } \\
& \text { - Electricity - interpolated } \\
& \text { - Telecoms } \\
& \text { - Telecoms - interpolated } \\
& \text { - Water } \\
& \text {-Water - interpolated } \\
& \text { 드 Convex hull } \\
& \text { Test pit } \\
& \text { - Test pits }
\end{aligned}
$$

Figure 5. Trial pit 2 showing the exposed assets together with the verified depth information and the photos taken on the day

the electricity interpretations. The excavation revealed four live and four earthed cables to the east of the telecoms conduit in close spatial proximity, yet there is the possibility that there are more cables underneath. The spatial interpretation of the excavation in the verification survey resulted in two lines representing these four cables. However, trial pit 2 is the intermediary pit of a sequence that follows a linear array of telecoms and electricity assets, pits 6 and 10 being the other pits in this sequence. Both these latter pits contained at least two lines representing electricity assets. It is clear that electricity cables in close proximity may be difficult to differentiate in the sensor responses.

All four companies detected the telecoms network (conduit V3). Companies A, B and C detected a single conduit, while company $\mathrm{E}$ detected two discrete conduits. E2 has been flagged as a misinterpretation based on the misinterpretation of the telecoms route from trial pit 6. Companies A, B and $\mathrm{E}$ have assigned a PAS128 quality level of QLB1 and each of these companies pass the horizontal specification, while companies $\mathrm{A}$ and $\mathrm{E}$ fail the vertical specification. However, if the spatial accuracy was set to QLB2, both companies would pass the vertical specification.

Trial pit 8 (see Figure 7) contained water, electricity and drainage assets, while trial pit 18 was designed to verify the location of electricity and telecommunications cables. Figure 8 shows the results for all four companies in relation to trial pits 8 and 18. All four companies detected the water network (V1). Companies A and E had assigned a PAS128 quality level of QLB2 and both passed the horizontal and vertical specifications. Company B had claimed a QLB1 and passed the 

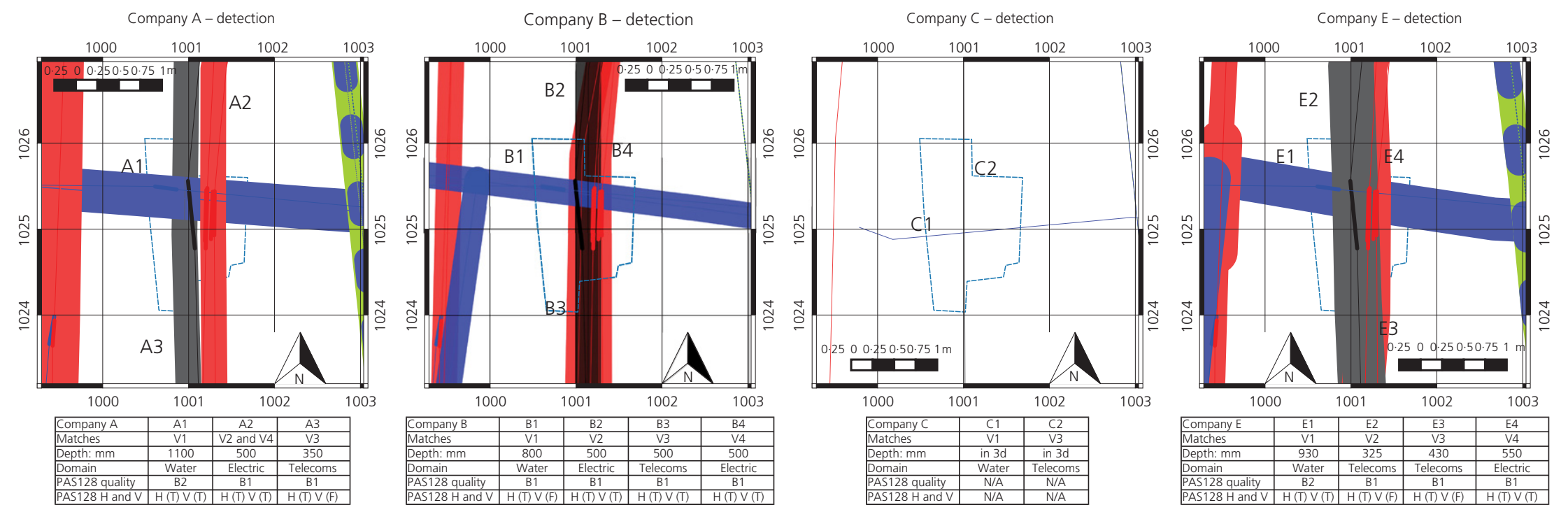

Utility features with extrapolation

- Electricity

- Electricity - interpolated

- Telecoms

- Telecoms - interpolated

- Water

D. Convex hull

Test pit

Figure 6. Location of trial pit 2 with the detected features and verified, by excavation for (a) company A, (b) company B, (c) company C and (d) company E

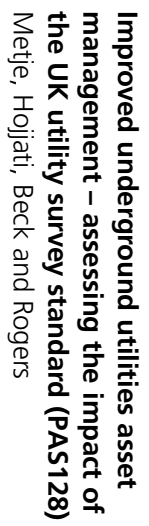



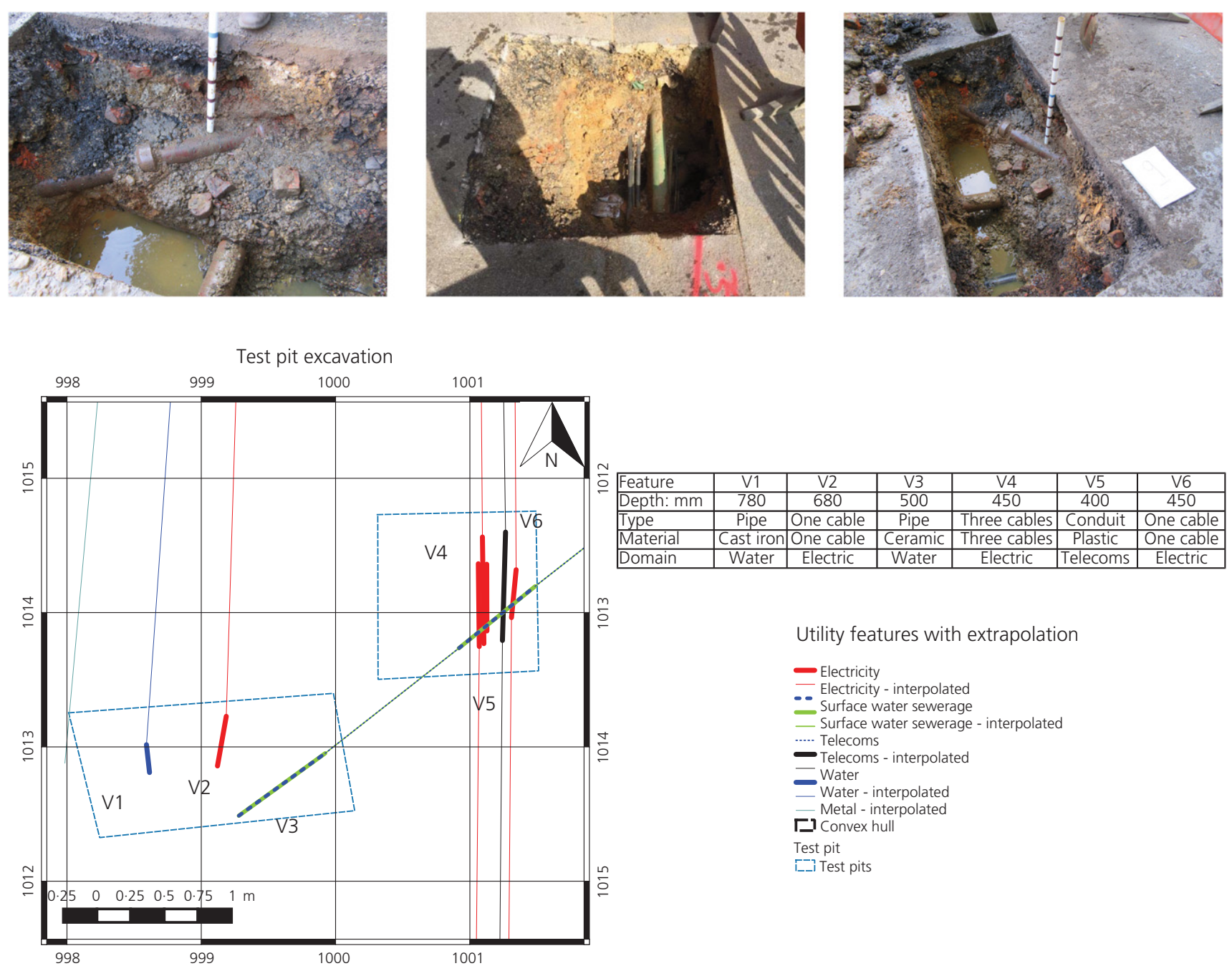

Figure 7. Trial pits 8 and 18 showing the exposed assets together with the verified depth information and the photos taken on the day

horizontal specification, but failed the vertical specification; however, company B would have passed the vertical specification at QLB2. All four companies detected the electricity network (V2). Only one cable was observed in the verification excavation and this was interpreted with a single line (V2). Companies A, B and E had a stated PAS128 QLB1. Interestingly, all companies failed the vertical specification, yet all would have passed the vertical and horizontal specification at a QLB2. Company B detected a further cable (B0) which should have appeared in this excavated trench, and yet the trench might have needed to be extended further to the east to reveal this feature if there was some horizontal inaccuracy. Hence, there is still some uncertainty surrounding whether this feature was correctly detected or not. Given the high risk associated with these feature types, this omission could have significant consequences.
No company detected the drainage network (V3), and thus for a $500 \mathrm{~mm}$ machine bucket no company provided adequate spatial information. On the basis of orientation, it is likely that this feature connects to the other drainage network feature revealed in trial pit 7 , and therefore it is surprising that no company detected this extensive feature.

Companies A, B and E detected the electricity network (cables V4 and V6). Company C, however, did not detect this high-risk electricity network. There remains some uncertainty with the electricity interpretations. The excavation revealed live and earthed cables on either side of the $\mathrm{N}-\mathrm{S}$ route of the telecoms conduit (V5) in close spatial proximity, yet there is the possibility that there are more located underneath. The spatial interpretation of the excavation in the verification survey resulted in two lines representing the cables. It is clear that 


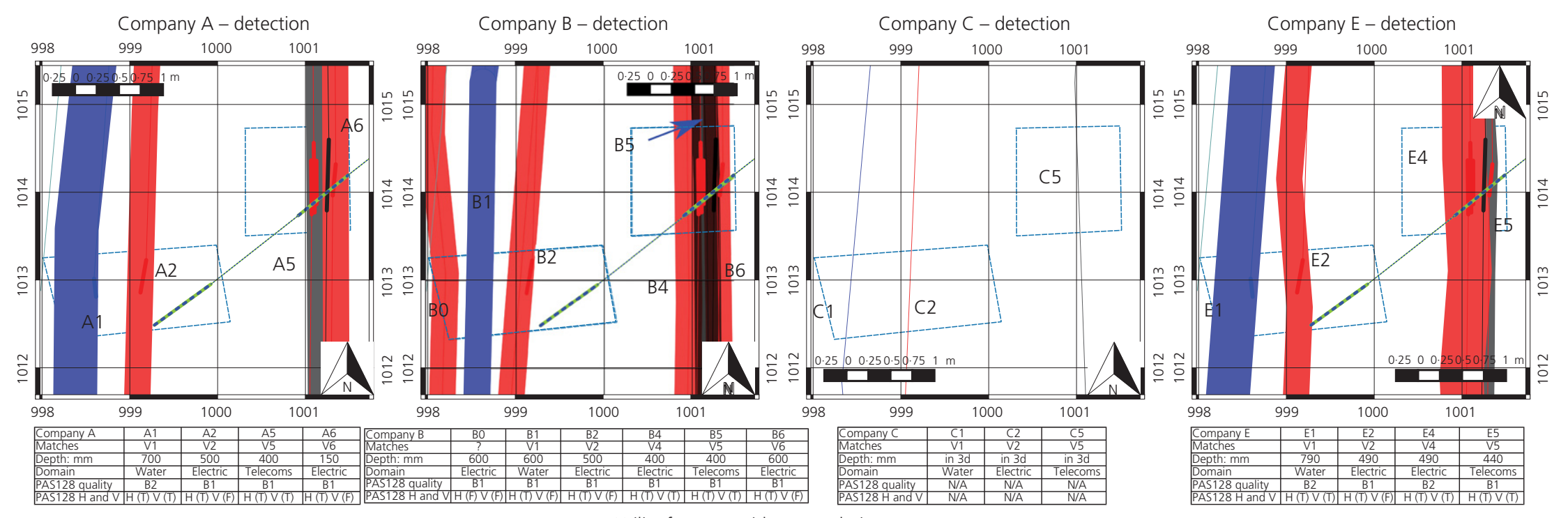

$$
\begin{aligned}
& \text { Utility features with extrapolation } \\
& \text { - Electricity } \\
& \begin{array}{l}
\text {-- Electricity - interpolated } \\
\text { - Surface water sewerage } \\
\text { Surface water sewerage - interpolated }
\end{array} \\
& \text { - Telecoms } \\
& \text { = Water } \\
& \text { - Metal - interpolated } \\
& \text { D. Convex hull } \\
& \text { Test pit } \\
& \text { [-ב Test pits }
\end{aligned}
$$

Figure 8. Location of trial pits 8 and 18 with the detected features and verified, by excavation for (a) company A, (b) company B, (c) company C and (d) company E

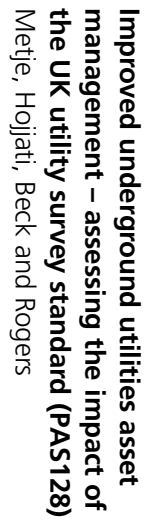



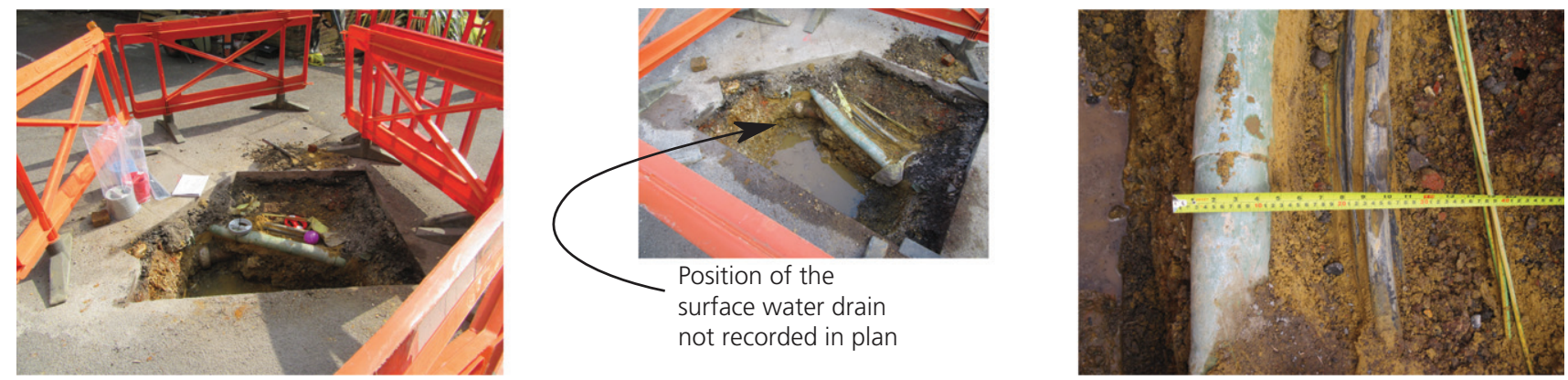

Test pit excavation

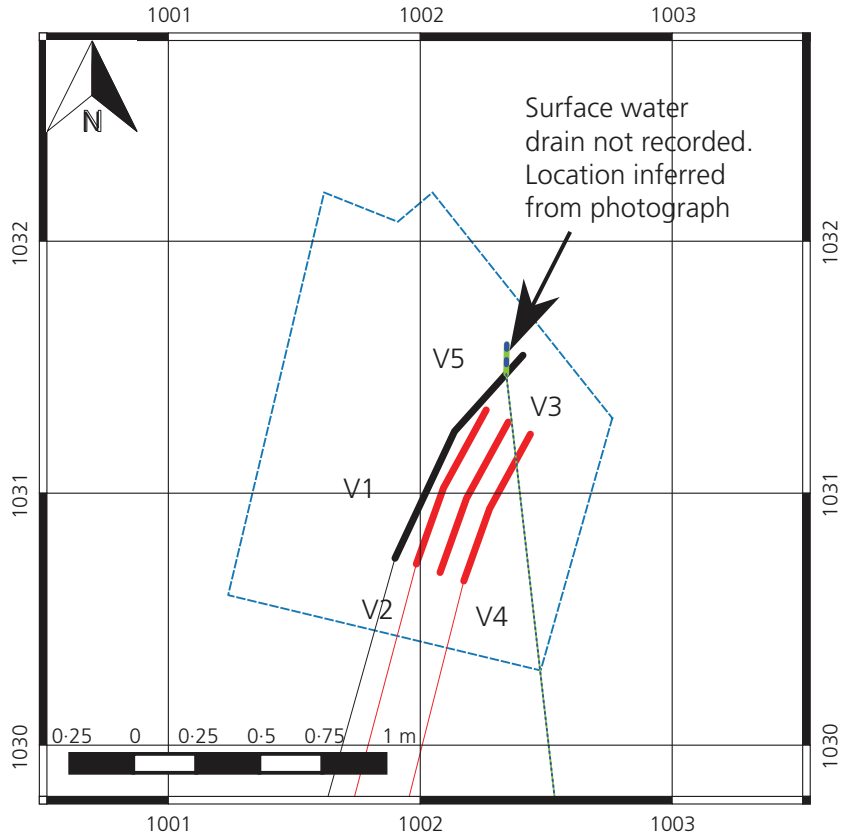

\begin{tabular}{|l|c|c|c|c|c|}
\hline Feature & $\mathrm{V} 1$ & $\mathrm{~V} 2$ & $\mathrm{~V} 3$ & $\mathrm{~V} 4$ & $\mathrm{~V} 5$ \\
\hline Depth: $\mathrm{mm}$ & 240 & 240 & 240 & 240 & 330 \\
\hline Type & Conduit & Four cables & Four cables & Four cables & Pipe \\
\hline Material & Plastic & Four cables & Four cables & Four cables & Ceramic \\
\hline Domain & Telecoms & Electric & Electric & Electric & Water \\
\hline
\end{tabular}

Utility features with extrapolation

- Electricity

- Electricity - interpolated

- Surface water sewerage

-... Telecoms

- Telecoms - interpolated

ㄱ Convex hull

Test pit

구 Test pits

Figure 9. Trial pit 10 showing the exposed assets together with the verified depth information and the photographs taken on the day

electricity cables in close proximity may be difficult to disambiguate in sensor responses and, given such ambiguities, a PAS128 analysis is inappropriate. All four companies detected the telecoms network (conduit V5). All companies except company $\mathrm{C}$ designated this feature as a PAS128 QLB1 and all companies were within horizontal and vertical specification.

Trial pit 10 (see Figure 9) contained telecoms, electricity and drainage assets and appears to be partially excavated and partially recorded. The eastern side of the excavation beyond the telecoms conduit (V1) revealed the collection of four electricity cables, but nothing lower; hence, it has been classed as partially excavated. The location of the drainage pipe (V5) was not recorded in plan; rather it has been inferred from the photograph (see Figure 9) and hence it is designated as partially recorded.

Figure 10 shows the results for the four survey companies. All four companies detected the telecoms network (V1). Companies A, B and $\mathrm{C}$ detected a single conduit, while company $\mathrm{E}$ detected two discrete conduits. E0 has been flagged as a misinterpretation based on the misinterpretation of the telecoms route from trial pit 6. Companies A and B have claimed a PAS128 QLB1 and, while each of these companies passes the horizontal specification, both fail the vertical specification. However, if the spatial accuracy was set to QLB2 both companies would pass the vertical specification. Company E has claimed a PAS128 QLB2; in this case it passes the horizontal specification, but fails the vertical specification. 


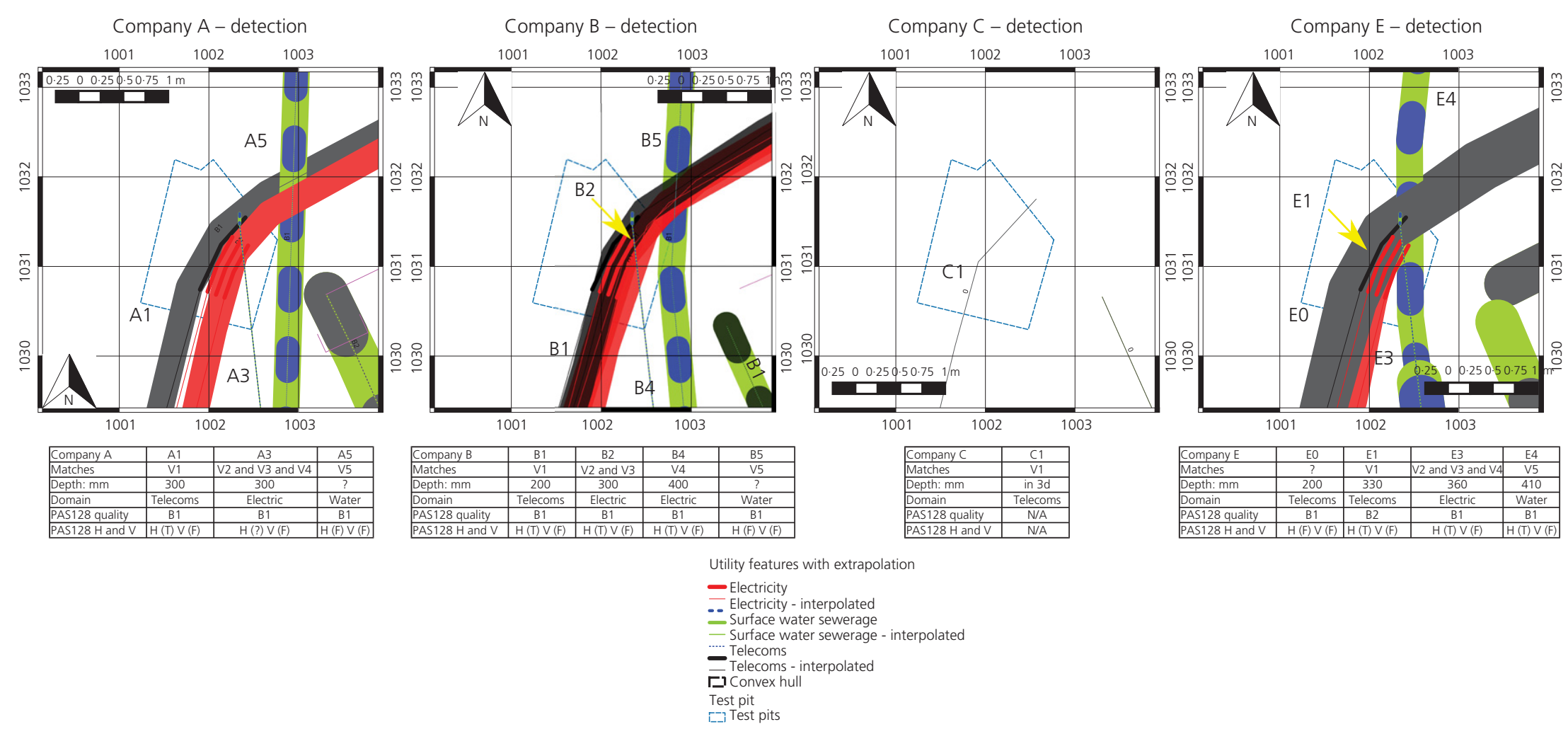

Figure 10. Location of trial pit 10 with the detected features and verified, by excavation for (a) company A, (b) company B, (c) company C and (d) company E

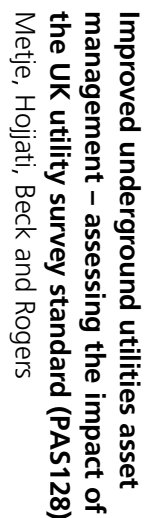


Table 2. Summary of test pit data and compliance with PAS128

\begin{tabular}{|c|c|c|c|c|c|c|c|c|c|c|c|c|c|c|c|c|}
\hline \multirow{2}{*}{$\begin{array}{l}\text { Trial hole } \\
\text { number }\end{array}$} & \multirow{2}{*}{ Asset } & \multirow{2}{*}{ Type } & \multirow{2}{*}{ Verified material } & \multirow{2}{*}{$\begin{array}{l}\text { Depth } \\
\text { (verified): } \\
\mathrm{mm}\end{array}$} & \multicolumn{4}{|c|}{ A } & \multicolumn{4}{|c|}{ B } & \multicolumn{4}{|c|}{ E } \\
\hline & & & & & & $\mathrm{H}$ & V & Depth: mm & & $\mathrm{H}$ & V & Depth: mm & & $\mathrm{H}$ & V & Depth: $\mathrm{mm}$ \\
\hline \multirow[t]{5}{*}{1 and 17} & V1 & Telecoms & Plastic - Conduit & 500 & B1 & $\mathrm{T}$ & $\mathrm{T}$ & 500 & B1 & T & $\mathrm{F}$ & 400 & B1 & T & $\mathrm{T}$ & 550 \\
\hline & V2 & Telecoms & Plastic - Conduit & 500 & B1 & $\mathrm{T}$ & T & 500 & B1 & $\mathrm{T}$ & T & 500 & B1 & T & T & 550 \\
\hline & V3 & Unknown & Metal - Pipe & 900 & N/A & $\mathrm{N} / \mathrm{A}$ & N/A & N/A & B1 & T & T & 900 & N/A & $\mathrm{N} / \mathrm{A}$ & N/A & $\mathrm{N} / \mathrm{A}$ \\
\hline & V4 & Water & Metal - Pipe & 1050 & B2 & $\mathrm{F}$ & $\mathrm{T}$ & 800 & B1 & T & $\mathrm{F}$ & 800 & B2 & T & T & 1120 \\
\hline & V5 & Electric & Metal - Cable & 750 & B2 & $\mathrm{T}$ & T & 600 & B1 & T & $\mathrm{F}$ & 600 & B1 & T & T & 810 \\
\hline \multirow[t]{4}{*}{2} & V1 & Water & Cast iron - Pipe & 1050 & B2 & $T$ & $\mathrm{~T}$ & 1100 & B1 & T & $\mathrm{F}$ & 800 & B2 & T & $\mathrm{T}$ & 930 \\
\hline & V2 & Electric & Cables & 550 & B1 & $\mathrm{T}$ & $\mathrm{T}$ & 500 & B1 & T & T & 500 & B1 & T & $\mathrm{F}$ & 325 \\
\hline & V3 & Telecoms & Plastic - Conduit & 550 & B1 & $\mathrm{T}$ & $\mathrm{F}$ & 350 & B1 & T & T & 500 & B1 & T & $\mathrm{F}$ & 430 \\
\hline & V4 & Electric & Cables & 550 & B1 & $T$ & T & 500 & B1 & T & T & 500 & B1 & T & T & 550 \\
\hline 3 & V1 & Water & Cast iron - Pipe & 940 & B2 & $\mathrm{F}$ & $\mathrm{F}$ & 1100 & B1 & $\mathrm{F}$ & $\mathrm{F}$ & 750 & B4 & $\mathrm{N} / \mathrm{A}$ & N/A & N/A \\
\hline \multirow[t]{7}{*}{4} & $\mathrm{~V} 1$ & Telecoms & Plastic - Conduit & 150 & B1 & $\mathrm{F}$ & $\mathrm{F}$ & 190 & B1 & T & $\mathrm{F}$ & 700 & B2 & $\mathrm{T}$ & $\mathrm{T}$ & 150 \\
\hline & V2 & Telecoms & Plastic - Conduit & 150 & B1 & $T$ & $\mathrm{~F}$ & 190 & B1 & T & $\mathrm{F}$ & 700 & B1 & T & T & 150 \\
\hline & V3 & Water & Plastic - Pipe & 600 & N/A & N/A & N/A & N/A & N/A & N/A & N/A & N/A & N/A & N/A & N/A & N/A \\
\hline & V4 & Water & Cast iron - Pipe & 850 & N/A & N/A & N/A & N/A & B1 & T & $\mathrm{F}$ & 600 & B2 & T & T & 950 \\
\hline & V5 & Gas & Plastic - Pipe & 500 & N/A & $\mathrm{N} / \mathrm{A}$ & N/A & N/A & N/A & N/A & N/A & $\mathrm{N} / \mathrm{A}$ & N/A & $\mathrm{N} / \mathrm{A}$ & N/A & N/A \\
\hline & V6 & Electric & Metal - Cable & 450 & B1 & $\mathrm{T}$ & $\mathrm{F}$ & 230 & B1 & $T$ & $\mathrm{~T}$ & 500 & N/A & N/A & N/A & N/A \\
\hline & V7 & Telecoms & Plastic - Conduit & 400 & B1 & $\mathrm{T}$ & $\mathrm{F}$ & 200 & B1 & $\mathrm{F}$ & $\mathrm{F}$ & 300 & B1 & T & $\mathrm{F}$ & 250 \\
\hline \multirow[t]{6}{*}{5} & V1 & Telecoms & Plastic-Conduit & 200 & B1 & $\mathrm{F}$ & $\mathrm{F}$ & 380 & B1 & T & $\mathrm{F}$ & 400 & B1 & T & $\mathrm{F}$ & 500 \\
\hline & V2 & Telecoms & Plastic - Conduit & 200 & B1 & $\mathrm{F}$ & $\mathrm{F}$ & 380 & B1 & T & $\mathrm{F}$ & 380 & B1 & T & $\mathrm{F}$ & 440 \\
\hline & V3 & Telecoms & Plastic - Conduit & 280 & B1 & $T$ & T & 220 & B1 & T & $\mathrm{F}$ & 500 & B2 & T & T & 250 \\
\hline & V4 & Telecoms & Plastic - Conduit & 280 & B1 & $\mathrm{T}$ & $\mathrm{F}$ & 220 & B1 & T & $\mathrm{F}$ & 500 & B2 & T & T & 250 \\
\hline & V5 & Water & Plastic - Pipe & 650 & N/A & $\mathrm{N} / \mathrm{A}$ & N/A & N/A & N/A & N/A & N/A & $\mathrm{N} / \mathrm{A}$ & N/A & $\mathrm{N} / \mathrm{A}$ & N/A & N/A \\
\hline & V6 & Water & Plastic - Pipe & 1150 & N/A & N/A & N/A & N/A & B1 & $T$ & $\mathrm{~F}$ & 900 & B3 & $\mathrm{T}$ & $\mathrm{T}$ & 1000 \\
\hline \multirow[t]{5}{*}{6} & $\mathrm{~V} 1$ & Electric & Cables & 500 & B1 & $\mathrm{T}$ & $T$ & 350 & B1 & T & T & 500 & B2 & T & T & 450 \\
\hline & V2 & Telecoms & Plastic - Conduit & 430 & B1 & $\mathrm{T}$ & T & 350 & B1 & T & T & 400 & B1 & T & T & 380 \\
\hline & V3 & Electric & Cables & 500 & B1 & $\mathrm{T}$ & T & 350 & B1 & T & $\mathrm{F}$ & 300 & B2 & T & T & 450 \\
\hline & V4 & Telecoms & Plastic - Conduit & 600 & B1 & $\mathrm{T}$ & T & 500 & B1 & T & $\mathrm{F}$ & 400 & B1 & T & T & 535 \\
\hline & V5 & Telecoms & Plastic - Conduit & 600 & N/A & N/A & N/A & N/A & B1 & T & $\mathrm{F}$ & 450 & B2 & $\mathrm{F}$ & T & 480 \\
\hline \multirow[t]{3}{*}{7} & $\mathrm{~V} 1$ & Telecoms & Plastic - Conduit & 400 & B1 & $T$ & $\mathrm{~T}$ & 450 & B1 & T & T & 500 & B1 & T & T & 500 \\
\hline & V2 & Telecoms & Plastic - Conduit & 400 & B1 & $\mathrm{T}$ & T & 450 & B1 & T & T & 400 & B2 & T & $\mathrm{F}$ & 480 \\
\hline & V3 & Water & Ceramic - Pipe & 500 & N/A & $\mathrm{N} / \mathrm{A}$ & N/A & N/A & N/A & N/A & N/A & N/A & N/A & N/A & N/A & N/A \\
\hline \multirow[t]{6}{*}{8 and 18} & V1 & Water & Cast iron - Pipe & 780 & B2 & $\mathrm{T}$ & T & 700 & B1 & T & $\mathrm{F}$ & 600 & B2 & T & T & 790 \\
\hline & V2 & Electric & Cable & 680 & B1 & $\mathrm{T}$ & $\mathrm{F}$ & 500 & B1 & T & $\mathrm{F}$ & 500 & B1 & T & $\mathrm{F}$ & 490 \\
\hline & V3 & Water & Ceramic - Pipe & 500 & N/A & N/A & N/A & N/A & N/A & N/A & N/A & N/A & N/A & $\mathrm{N} / \mathrm{A}$ & $\mathrm{N} / \mathrm{A}$ & N/A \\
\hline & V4 & Electric & Cable & 450 & N/A & N/A & N/A & N/A & B1 & $\mathrm{T}$ & $\mathrm{T}$ & 400 & B2 & $\mathrm{T}$ & $\mathrm{T}$ & 490 \\
\hline & V5 & Telecoms & Plastic - Conduit & 400 & B1 & $\mathrm{T}$ & $T$ & 400 & B1 & T & T & 400 & B1 & T & T & 440 \\
\hline & V6 & Electric & Cable & 450 & B1 & $\mathrm{T}$ & $\mathrm{F}$ & 150 & B1 & T & $\mathrm{F}$ & 600 & N/A & N/A & N/A & N/A \\
\hline \multirow[t]{5}{*}{10} & $\mathrm{~V} 1$ & Telecoms & Plastic - Conduit & 240 & B1 & $\mathrm{T}$ & $\mathrm{F}$ & 300 & B1 & T & $\mathrm{F}$ & 200 & B2 & $T$ & $\mathrm{~F}$ & 330 \\
\hline & V2 & Electric & Cables & 240 & B1 & ? & $\mathrm{F}$ & 300 & B1 & T & $\mathrm{F}$ & 300 & B1 & T & $\mathrm{F}$ & 360 \\
\hline & V3 & Electric & Cables & 240 & B1 & ? & $\mathrm{F}$ & 300 & B1 & T & $\mathrm{F}$ & 300 & B1 & T & $\mathrm{F}$ & 360 \\
\hline & V4 & Electric & Cables & 240 & B1 & ? & $\mathrm{F}$ & 300 & B1 & T & $\mathrm{F}$ & 400 & B1 & T & $\mathrm{F}$ & 360 \\
\hline & V5 & Water & Ceramic - Pipe & 330 & B1 & $\mathrm{F}$ & $\mathrm{F}$ & $?$ & B1 & $\mathrm{F}$ & $\mathrm{F}$ & $?$ & B1 & T & $\mathrm{F}$ & 410 \\
\hline
\end{tabular}




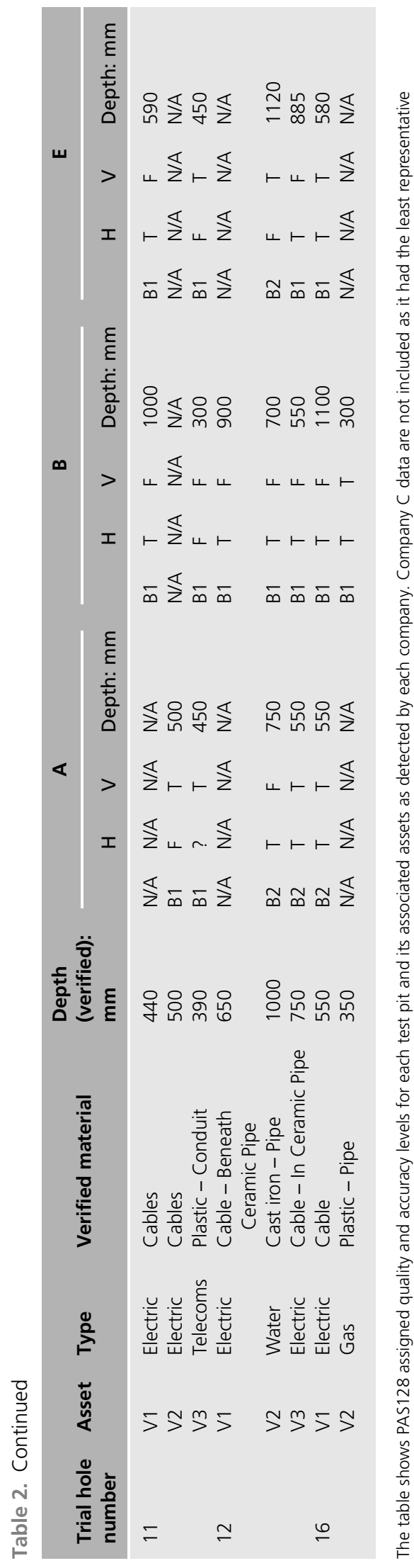

Companies A, B and E detected the electricity network (cables V2, V3 and V4). Company C did not detect the highrisk electricity network. However, there remains some uncertainty with the electricity interpretations: the excavation revealed four live and four earthed cables to the east of the telecoms conduit in close spatial proximity, but there is the possibility that there are more located underneath. The spatial interpretation of the excavation in the verification survey resulted in three lines representing these four cables. This network extends into trial pit 2 followed by trial pit 6 . The verification survey interpreted one line and two lines, respectively. This reinforces the observations made earlier that electricity cables in close proximity may be difficult to disambiguate in sensor responses and that a PAS128 analysis is inappropriate.

It should be noted that there is some spatial uncertainty about the location of the drainage pipe (V5) from the verification survey. Companies A, B and E detected the drainage network, while company $\mathrm{C}$ did not. Moreover, in relation to a $500 \mathrm{~mm}$ machine bucket only company $\mathrm{E}$ provided adequate planimetric spatial information, while in relation to the stated PAS128 QLs only company E passes the horizontal specification. Indeed, at a quality level of QLB2 all other companies still fail.

Table 2 shows the analysis of all the trial pits with respect to whether an asset was verified and whether the PAS128 (BSI, 2014) quality level designation was achieved. Overall, it became apparent that most assets were detected successfully, but that the accuracy associated with a QLB1 designation was often not achieved for the vertical location, while a QLB2 level accuracy would have been achieved in most places. This puts into question the definition in PAS128 on the QLs, since the detection of a feature by two different sensing technologies does not necessarily increase the accuracy, as suggested by PAS128, but increases the confidence that a utility service exists beneath the surface at that point. Therefore, on the basis of this observation it is recommended that a differentiation is made between accuracy and confidence in any future revisions of PAS128.

The data were also analysed with respect to the completeness and accuracy of the feature. Analysis was carried out for every verification trial pit, where the focus was on the 'error of commission' and the 'error of omission'. An 'error of commission' is described explicitly as a detected feature, which is not verified by the trial pit excavations. An 'error of omission' is not including detected features that do exist. While errors of commission can have potentially serious consequences, they generally come with a 'health warning', inasmuch as they are likely to suggest that something lies in a corridor and it would be wise to check whether it does indeed appear to be present 
before engaging on an activity nearby. Errors of omission are potentially more serious since there is no such 'health warning' and a tendency to complacency might exist. Overall, six errors of omission features were found.

E1 - an electricity cable observed in trial pit 10

- E2 - an electricity cable observed in trial pit 12

- D1 - a drainage pipe observed in trial pit 8

- W1 - a water pipe observed in trial pit 4

W2 - a water pipe observed in trial pit 5

- G1 - a gas pipe observed in trial pit 4

E1 is a reflection of the way electricity cables are visualised, and this is discussed in greater detail in the following section. E2 is a true omission. Company B did detect this feature, but no other company detected it. It is possible that this feature was only detected by company B due to anomalous loadings on the cable at the time of survey. This is a significant omission due to the risks associated with utility strikes involving electricity cables. Likewise, D1 is a true omission, although in this case no company detected the drainage feature in trial pits 7 and 8 . While some companies detected the part of the surface water sewerage feature in the observation chamber (a visual inspection), this feature was reported as blocked. Furthermore, there was no surface scarring associated with the drain, which could have provided a visual clue on the existence of the feature. This has an interesting implication: the interpretation by the utility companies may not be completely objective in terms of the geophysical data - companies may, and indeed should, be influenced by observed features (such as surface scarring, surface utility furniture, access to subsurface observation chambers etc.), whereas the converse is also possible: if there is no visual feature, and the sensors indicate there is nothing present, then false confidence may preclude further searching. This needs further exploration with the survey companies. In this case, a slightly different variation on this tendency might arise: it may be that a blocked feature means that any further signal anomalies are ignored. W1, a small diameter plastic water pipe, W2, a plastic water pipe and G1, a plastic gas pipe, are true omissions as no company detected these features, and the latter omission has the most severe potential consequences. Two trial pits contained errors of commission. Proximity to buildings appears to be one of the biggest problems for drainage asset types.

\section{Discussion}

There are several different interpretations associated with electricity cables. It is clear that companies B and E have identified the majority of electricity assets, while company B has detected all the electricity features in the verification survey and company $\mathrm{C}$ has significantly under-represented the electricity assets in its survey results. Moreover, there was significant diversity in feature representation by the different companies. Company $\mathrm{B}$ provided the most representative results in terms of the excavated trial pits and company $\mathrm{C}$ the least representative. The differences are likely due, in part, to the difficulty of discerning more than one co-located cable as discrete assets.

There is significant diversity in the detection of the drainage network between survey companies. This does indicate uncertainty in detection. This is compounded by the excavation of a surface water sewerage pipe that was not detected by any survey company. Further excavation would be needed to test the reliability of drainage detection, yet there is evidence that the unwarranted connection between surface and buried features can result in errors just as much as if surface features are overlooked. This requires a particular rigour in reporting what is known, what is strongly implied on the basis of data, and what is assumed on the basis of logic or supposition.

There is strong agreement between the companies on the location of the telecom ducts. While the shape of the network is generally agreed by all companies, there were differences in the number of telecom ducts detected by the sensors during the survey. However, this should have no material impact on the excavation strategy, since they were closely co-located, as long as those responsible for excavation are sufficiently aware to explore either side of a duct that is exposed: thinking there is one from a survey and finding one in the edge of an excavation does not mean that there is no parallel duct on the other side. There is equally the possibility that the accuracy of the identification of telecoms might relate to the use of observation chambers. In such a scenario, the interpretation could be based on sensor observations remote from the chambers that is, known locations (observed in observation chambers) are joined by subsurface detection. The indication is that all companies can detect telecom features reliably.

The water network is mainly coherent with some minor disagreements in network connectivity. The major issue was the lack of detection of the small diameter plastic pipe observed in trial pits 4 and 5 .

Overall, it is evident that there is good agreement between the different survey results suggesting that the introduction of PAS128 (BSI, 2014) has had a positive impact on the industry. This was also confirmed by experience from industry, for example where practitioners stated that the success in detection and location of buried utilities tripled at Heathrow Airport in an area that has been previously mapped and was previously assumed to have excellent information (BSI, 2016). The biggest differences appear to be in the detection of electricity and drainage assets. 
However, when looking into more detail in the PAS128 quality level specifications, it became apparent that the vertical accuracies according to QLB1 were rarely achieved. Nevertheless, it is worth noting that if the designated quality level had been changed to QLB2, most assets would have been detected with the associated horizontal and vertical accuracies. This suggests that survey companies need to assess more carefully their confidence when assigning a QLB1 to the detection of an asset as this confidence might not be reflected in reality. Moreover, the definition for QLB1 in PAS128 needs reviewing. Having two different technologies providing a strong signal indicating the detection of a buried feature increases the surveyor's confidence in the detection of this asset, but does not increase the accuracy as each technology has its own accuracy depending, for example, on frequency, soil type and conditions, asset size and material. Accuracies as defined in QLB2 would, in most cases, provide safe mechanical digging (assuming a bucket width of $500 \mathrm{~mm}$ ). However, where there is limited space within the subsurface and for future designs, a greater location accuracy, such as suggested by QLB1, might be desirable.

Detection of drainage assets seemed to be a particular problem close to buildings. The methodologies used for detecting drainage close to buildings by survey companies need to be reviewed. It should also be noted that all survey technologies based on sending an electromagnetic signal through the ground are affected by different ground conditions (type of soil, water content), especially with respect to determining the accurate depth of the asset. Survey equipment is calibrated for average conditions - for example, average velocity for groundpenetrating radar (GPR), and this is sometimes regarded as 'good enough'. This issue can be overcome by testing the ground conditions at the time of survey (Curioni et al., 2017) or by checking the detected depth against the measured depth at all inspection chambers and adjusting the detected depths accordingly. Nevertheless, the issue of increased confidence against increased accuracy, which is conflated in PAS128, remains. Another issue highlighted by the practitioners is that depths are commonly rounded down to the nearest decimetre on the premise that showing a shallower depth is safer than showing a deeper depth. This is a valid point, however, the issue with the definition for QLB1 remains and, ultimately it is up to the practitioner to assign the appropriate quality level according to PAS128 (BSI, 2014).

More recently, not only is the location of the buried assets cited as being important to asset owners, but also the condition of the assets to help identify the most appropriate intervention methods. Accordingly, the Assessing The Underworld (ATU) project researched techniques to monitor remotely the condition of buried utilities (see Figure 11; ATU, 2018; Rogers, 2015). It did so by using the geophysical tools combined in the MTU multi-sensor platform to assess the condition of the buried utility infrastructure (pipelines and cables), the geotechnical infrastructure (the ground in which the utility services are buried), and the surface transport infrastructure (roads and pedestrian areas beneath which the utilities are buried; Rogers et al., 2012). It also advanced appreciation of how to make underground utility streetworks operations more sustainable by developing a proof-of-concept decision support system (DSS), to integrate the information from utility surveys with the utility service companies' records in a single, integrated and searchable platform (Clarke et al., 2017). In addition, a sustainability evaluation system set within a value-based asset management framework, was developed and tested to assess the wider long-term costs and impacts of underground utility streetworks operations in urban areas (Hojjati et al., 2016, 2017, 2018). All of this led ultimately to better understanding the engineering context of the next-generation underground utility infrastructure (Rogers et al., 2017).

Furthermore, the newly published PAS256: Buried Assets Capturing, recording, maintaining and sharing of location information and data - Code of practice (BSI, 2017) was developed, as a result of extensive input and collaboration from the industry stakeholders, in line with PAS128 to improve data management for, and in turn engineering practices related to, buried underground utility assets.

\section{Conclusions and recommendations}

Four geophysical survey companies provided comprehensive datasets resulting from a trial during a $9 \mathrm{~d}$ period in March 2015 to detect all buried assets on a small car park at the University of Southampton. Based on their results, a control area was determined for which all companies provided results. The results were compared with each other and also with the as-built information obtained from 14 trial pits. In addition, compliance with the PAS128 QLs was assessed for the excavated assets.

Overall, it is very encouraging that there is a good agreement for the different utility types detected by the four survey companies. The results showed that there was good agreement in terms of length of utility service detected by all companies for the water and telecoms networks. The biggest differences observed were for the drainage and electricity utility networks. The investigation showed that an electricity cable and a drainage pipe remained undetected (with the exception that a single company detected the electricity cable). The electricity network had a range of observed lengths that differed by up to $149 \mathrm{~m}$. When looking at the difference in the detection of the electricity cables, it became clear that there were different interpretations associated with this utility type, while the possible reason that only one survey company located the otherwise undetected electricity cable was that it was only subjected to a significant electrical load on the day that that company 


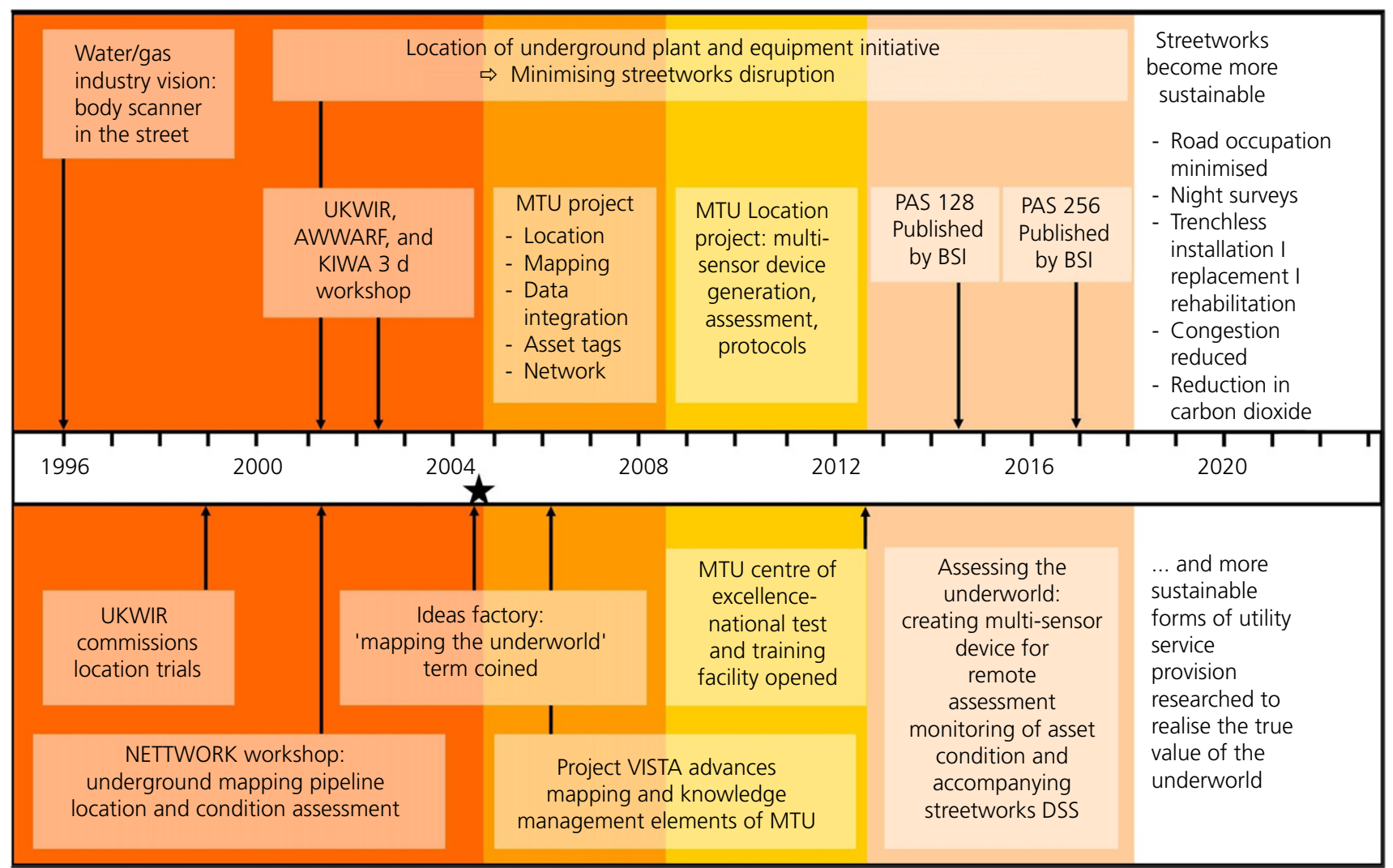

Figure 11. MTU and ATU research timeline demonstrating a 25 year vision towards more sustainable underground utility streetworks (Metje et al., 2018)

surveyed; without such a load it would have remained 'invisible' to the sensors. There was also significant diversity in feature representation by the different companies. Moreover, some companies conflated electricity cables in close proximity to one asset, which explains the difference in the physical length detected by the different survey companies.

Investigating the compliance with PAS128 QLs was revealing: in most cases where a QLB1 was designated for the detected asset, this was not achieved, though with better compliance for horizontal as opposed to vertical accuracy (the accuracy criterion for which was frequently not met), while a QLB2 designation would have been achieved in almost all of these cases. For the next review of PAS128, the accuracy definitions for the different QLB levels should be reconsidered in light of the findings from this trial and discussions with the practitioners should elicit why it is difficult to achieve the stipulated accuracies in the vertical dimension.

Overall, the introduction of the PAS128 standard seems to have had a positive impact on the utility survey industry based on the findings reported herein combined with additional case studies. Therefore, industry should initiate some work on the achievability of QLB1 and reflect whether the criteria for assigning a QLB1 according to PAS128 are appropriate.

\section{Acknowledgements}

The research was supported by the UK Engineering and Physical Sciences Research Council (EPSRC) under the Mapping The Underworld (EP/F065965/1), Assessing The Underworld (EP/K021699/1) and Balancing the Impact of City Infrastructure Engineering on Natural Systems using Robots (EP/N010523/1) project grants. Moreover, the authors thank the participating survey companies for giving their time to perform the surveys and actively engaging in analysing the results.

\section{REFERENCES}

ASCE (American Society of Civil Engineers) (2002) ASCE 38-02: Standard guideline for the collection and depiction of existing subsurface utility data. American Society of Civil Engineers, Reston, VA, USA. 
Ashdown C (2001) Mains Location Equipment a State of the Art Review and Future Research Needs - Final Report. UK Water Industry Research, London, UK, UKWIR report number: 01/WM/06/1.

ATU (Assessing The Underworld) (2018) Assessing The Underworld. ATU, UK. See http://www.assessingtheunderworld.org/ (accessed 01/10/2018).

BSI (2014) PAS 128: 2014: Specification for underground utility detection, verification and location. BSI, London, UK.

BSI (2016) BSI and Institution of Civil Engineers lead industry collaboration PAS 128 builds trust in underground utility detection sector, BSI PAS128 case study. BSI, London, UK.

BSI (2017) PAS 256: 2017: Buried assets - capturing, recording, maintaining and sharing of location information and data - code of practice. BSI, London, UK

Burtwell MH, Faragher E, Neville D et al. (2003) Locating Underground Plant and Equipment - Proposals for a Research Programme. UK Water Industry Research, London, UK, UKWIR Report (Reference Number 03/WM/12/4)

Chapman DN, Costello JB and Rogers CDF (2002) Report on Asset Location and Condition Assessment. UK Water Industry Research, London, UK, UKWIR Research Report (Reference Number $02 / \mathrm{WM} / 12 / 1)$

Clarke BG, Magee D, Dimitrova V et al. (2017) A decision support system to proactively manage subsurface utilities. Proc. of International Symposium for Next Generation Infrastructure (ISNGI 2017), London, UK. pp. 99-108.

CSA (Canadian Standard Association) (2011) CSA 250-11: Mapping of underground utility infrastructure. Canadian Standard Association, Mississauga, Canada.

Curioni G, Chapman DN and Metje N (2017) Seasonal variations measured by TDR and GPR on an anthropogenic sandy soil and the implications for utility detection. Journal of Applied Geophysics 141: 34-46.

Gallienne B (2016) Delivering growth - the legislative and practical realities. National Joint Utilities Group (NJUG), Presentation at EUA Utility Street Works Conference: New Approaches for Critical Infrastructure, London, UK.

Hojjati A, Jefferson I, Metje N and Rogers CDF (2016) Sustainable asset management for utility streetworks. In Transforming the Future of Infrastructure through Smarter Information: Proceedings of the International Conference on Smart Infrastructure and Construction (ICSIC 2016) (Mair RJ, Soga K, Jin Y, Parlikad AL and Schooling JM (eds)). ICE Publishing, London, UK, pp. 669-674.

Hojjati A, Jefferson I, Metje N and Rogers CDF (2017) Embedding sustainability criteria into pre-appraisal of underground utility for future cities. Proceedings of the Institution of Civil Engineers Urban Design and Planning 170(6): 258-271, https:/doi.org/ 10.1680/jurdp.17.00023.

Hojjati A, Jefferson I, Metje N and Rogers CDF (2018) Sustainability assessment for urban underground utility infrastructure projects. Proceedings of the Institution of Civil Engineers Engineering Sustainability 171(2): 68-80, https://doi.org/ 10.1680/jensu. 16.00050

JUPEM (Jabatan Ukur dan Pemetaan Malaysia) (2006) Standard Guideline for Underground Utility Mapping. Department of Survey and Mapping, Jabatan Ukur dan Pemetaan Malaysia, Kuala Lumpur, Malaysia.

Kraus E, Obeng-Boampong K and Quiroga C (2012) Utility investigation trends in Texas. Transportation Research Record 2309: 209-217.

Lew JJ (1999) Cost Savings on Highway Projects Utilizing Subsurface Utility Engineering. Purdue University, Department of Construction Management, West Lafayette, IN, USA, Report FHWA DTFH61-96-00090.
Makana LO, Metje N, Jefferson I, Sackey M and Rogers CDF (2018) Cost estimation of utility strikes: towards proactive management of street works. Infrastructure Asset Management 1-34. https://doi.org/10.1680/jinam.17.00033.

McMahon W, Burtwell M and Evans M (2006) Minimising Street Works Disruption: The Real Costs of Street Works to the Utility Industry and Society. UK Water Industry Research, London, UK.

Metje N, Atkins P, Brennan M et al. (2007) Mapping the underworldstate-of-the-art review. Tunnelling and Underground Space Technology 22(5): 568-586.

Metje N, Rogers CDF and Parker J (2013) Making an Impact - from $B A C K$ to the Future. Mapping the Underworld, Birmingham, UK See http://www.mappingtheunderworld.ac.uk/MTU\%20Brochure $\%$ 20Final $\% 20$ Version.pdf (accessed 01/05/2018).

Metje N, Ahmad B and Crossland SM (2015) Causes, impacts and costs of strikes on buried utility assets. Proceedings of the ICE Municipal Engineer 168(3): 165-174, https://doi.org/10.1680/ jmuen.14.00035.

Metje N, Rogers CDF, Chapman DN et al. (2018) Advancing the ATU Roadmap from Sensors to Global Research Impact. Assessing The Underworld, Birmingham, UK. See http://assessingtheunderworld. org/wp-content/uploads/2014/02/ASSESSING-THE-

UNDERWORLD-BROCHURE_0318_high.pdf (accessed 01/10/2018).

MTU (Mapping The Underworld) (2013) Mapping The Underworld. MTU, UK. See http://www.mappingtheunderworld.ac.uk/ (accessed 01/05/2018)

Najafi M (2005) Trenchless Technology. McGraw-Hill, New York, NY, USA.

Osman $\mathrm{H}$ and El-Diraby T (2005) Subsurface utility engineering in Ontario: case studies \& lessons learned. 1st Infrastructure Technology, Management and Policy Specialty Conference at the 33rd Canadian Society of Civil Engineering Annual Conference, Toronto. Canadian Society of Civil Engineering (CSCE), Toronto, Canada, pp. FR-105-1-FR-105-9.

Osman $\mathrm{H}$ and El-Diraby T (2007) Implementation of subsurface utility engineering in Ontario: cases and a cost model. Canadian Journal of Civil Engineering 34(12): 1529-1541.

Parker J (2008a) Briefing: Minimising street works disruption - a multi-project research programme. Proceedings of the Institution of Civil Engineers - Municipal Engineer 161(2): 81-82, https://doi.org/10.1680/muen.2008.161.2.81.

Parker J (2008b) Briefing: The real cost of street works. Proceedings of the Institution of Civil Engineers - Transport 161(4): 175-176, https://doi.org/10.1680/tran.2008.161.4.175.

Rogers CDF (2015) Assessing the underworld - remote sensing to support smart and liveable cities. Keynote paper, 8 th International Workshop on Advanced Ground Penetrating Radar (IWAGPR 2015), Florence, Italy. IEEE, Florence, Italy, pp. 1-4

Rogers CDF, Chapman DN and Karri RS (2004) UK engineering network in Trenchless Technology (NETTWORK). Proceedings of International Conference on Plastic Pipes XII, Milan, Italy.

Rogers CDF and Chapman DN (2005) NETTWORK - establishing UK's research needs in trenchless technology. Proceedings of the 23rd International Conference on Trenchless Installation of Utilities (No-Dig 2005), Rotterdam, the Netherlands.

Rogers CDF, Hao T, Costello SB et al. (2012) Condition assessment of the surface and buried infrastructure - a proposal for integration. Tunnelling and Underground Space Technology 28: 202-211.

Rogers CDF, Metje N, Makana LO et al. (2017) Assessing the underworld - understanding the context for engineering the next generation infrastructure. Proceedings of International Symposium 
for Next Generation Infrastructure (ISNGI 2017), London, UK. pp. 341-350.

Royal ACD, Rogers CDF, Atkins PR et al. (2010) Briefing: Stakeholder perspectives of buried utility mapping. Proceedings of the Institution of Civil Engineers - Municipal Engineer 163(1): 3-7, https://doi.org/10.1680/muen.2010.163.1.3.

SA (Standard Australia) (2013) AS 5488-2013: Classification of Subsurface Utility Information (SUI). Standard Australia, Sydney, Australia.

SA (2018) DR AS 5488.1:2018: Classification of Subsurface Utility Information (SUI) Part 1: subsurface utility information. Standard Australia, Sydney, Australia.
Sinha SK, Thomas HR, Wang MC and Jung YJ (2007) Subsurface Utility Engineering Manual. Pennsylvania Transportation Institute, PA, USA, No. FHWA-PA-2007-027-510401-08. Thomas AM, Rogers CDF, Chapman DN, Metje N and Castle J (2009) Stakeholder needs for ground penetrating radar utility location. Journal of Applied Geophysics 67(4): 345-351.

Zembillas NM (2003) Subsurface utility engineering: a technologydriven process that results in increased safety, fewer claims, and lower costs. Proceedings of American Society of Civil Engineers Pipelines 2003 International Conference, Baltimore. American Society of Civil Engineers, Baltimore, MA, USA.

\section{How can you contribute?}

To discuss this paper, please email up to 500 words to the editor at journals@ice.org.uk. Your contribution will be forwarded to the author(s) for a reply and, if considered appropriate by the editorial board, it will be published as discussion in a future issue of the journal.

Proceedings journals rely entirely on contributions from the civil engineering profession (and allied disciplines). Information about how to submit your paper online is available at www.icevirtuallibrary.com/page/authors, where you will also find detailed author guidelines. 